\title{
European Space Research in the Meliing Pot
}

THE role to be played by Europe in space will probably be decided within the next two months. Following the abortive second session of the European Space Conference (ESC) which met in Brussels recently to consider NASA's proposals for a European share in the post-Apollo programme (see Nature, 228,$596 ; 1970$ ), the next planned step is the report now being prepared by a joint group from ELDO and ESRO on the feasibility of the shuttle proposals put forward by NASA. Moreover, the German delegation to the ESC, supported by the Belgian and French delegations, suggested that the deadline by which interested countries must decide which proposals they are prepared to support (if any) should be December 31 .

Like the Concorde project, the question of cooperation in space research is subject to political as well as economic factors. West Germany is particularly enthusiastic about working with NASA on the next generation of spacceraft, while France and Belgium support the idea with some reservations. Britain has refused to make any commitment without a more well-defined proposal from NASA, which at present wants the ESC to commit itself to something like a 10 per cent share in the still undefined cost of a project. Italy, Holland, Sweden and Norway are, like Britain, interested in the proposal but refuse to commit themselves without more information. Denmark is not interested in participating in any postApollo programme, and is also withdrawing from ESRO

On their own, the three firm supporters of participation in NASA's programme could supply only about 8 per cent of the total cost, and would therefore be in a very weak bargaining position when high level policy decisions are made. With the four more reluctant members of the ESC joining in, Europe might be able to provide a sufficient stake in the project for its voice to carry some weight at policy making levels. But even in the United States there is no consensus in favour of the shuttle and there is a possibility that if a majority of the European countries are against participating, the US Congress could be sufficiently influenced to cut back its space budget still furtheras yet, no endorsement of any post-Apollo manned space flight programme has been given.

A major source of the present confusion is the differing interpretations placed on NASA's offer to launch satellites for European countries provided that they join the space shuttle programme. Some have interpreted this as implying that NASA will not provide launch facilities for those who do not help with the shuttle; the British view is that American launch facilities will still be available on a basis similar to the arrangements under which the Skynet and Ariel satellites have been launched for Britain by NASA. This is also the reason for Britain's split with Germany and France over the development of the Europa 3 launcher and which caused the British withdrawal from ELDO. On the basis of three failures to send into orbit a European satellite, and Britain's own unhappy record with Black Arrow, the argument that Europe should concentrate on satellite development and leave launch facilities to the Americans is very strong. There is no question that the British Ariel satellites have contributed greatly to scientific knowledge (see page 700), and there are now financial rewards such as the recent contract between the Hughes Aircraft Corporation and the British Aircraft Corporation.

Already the largest supplier of satellites and components in Europe, BAC now has an order book worth roughly $\$ 10$ million, the recent contract with Hughes for components for the second generation of Intelsat 4 satellites accounting for one tenth of this total. BAC is also a partner in European aerospace consortia, and an interesting situation could arise if the countries in which their partners are based officially join the post-Apollo programme while Britain does not. In spite of the possibility of some political backlash affecting $\mathrm{BAC}$, it would still have a good chance of playing a major role in the development of Europe's share of the programme. Commercially, a continued European space effort on Europa 3 and applications satellites plus a share in the American space effort is the most attractive prospect, but in the face of any extravagant speculation it is salutary to remember that the highly successful Skylark sounding rocket has been both BAC's greatest single money earner in the field of space research and has also provided a wealth of scientific data for relatively little cost.

The political situation is, as ever, extremely complex. Non-cooperation by Britain could be used in Europe as a barrier to the application to join the Common Market, while at the other extreme, complete European participation in the shuttle project might be viewed with alarm in the Pentagon by those who are impressed by the military applications of the new spacecraft.

The future for a cooperative European space effort therefore looks extremely gloomy. Even the proposed merging of ELDO and ESRO to form a European Space Organization dealing with both launchers and satellites seems to be merely an administrative shuffle. But there are two points yet to be decided which could even now result in a combined European partnership working at a high level (rather than merely as glorified sub-contractors) on the next stage of the US space programme. Mr Frederick Corfield, the Minister of Aviation Supply, has made it clear that Britain is quite prepared to examine any concrete proposals made by NASA, and he is at present simply refusing to sign a blank cheque with little say in what the money is spent on.

If any progress in this direction is made, the Swiss have offered to act as hosts to the next meeting of the ESC, and this could make for a more coherent conference than the recent shambles in Brussels, which arose partly because the chairman (traditionally provided by the host country) was an outspoken supporter of the acceptance in full of NASA's proposals, and did not provide the relative degree of impartiality appropriate for his position. The exact position here is far from clear because technically the last meeting of the ESC was adjourned unfinished, and traditionally it should therefore reconvene in the same country. 